\title{
Human Umbilical Cord Mesenchymal Stem Cells Alleviate Concanavalin A-induced Fulminant Hepatitis by Repressing NF-kB Signaling and Glycolysis
}

\section{Lijie Pan}

Third Affiliated Hospital of Sun Yat-Sen University

Chang Liu

Third Affiliated Hospital of Sun Yat-Sen University

Qiuli Liu

Third Affiliated Hospital of Sun Yat-Sen University

Yanli Li

Third Affiliated Hospital of Sun Yat-Sen University

\section{Cong Du}

Third Affiliated Hospital of Sun Yat-Sen University

\section{Xinmei Kang}

Third Affiliated Hospital of Sun Yat-Sen University

\section{Shuai Dong}

Third Affiliated Hospital of Sun Yat-Sen University

\section{Zhuowei Zhou}

Third Affiliated Hospital of Sun Yat-Sen University

Huaxin Chen

Third Affiliated Hospital of Sun Yat-Sen University

\section{Xiaoqi Liang}

Third Affiliated Hospital of Sun Yat-Sen University

Jiajie Chu

Third Affiliated Hospital of Sun Yat-Sen University

yan xu ( $\sim$ xuyan55@mail.sysu.edu.cn )

Third Affiliated Hospital of Sun Yat-Sen University https://orcid.org/0000-0001-5653-291X

\section{Qi Zhang}

Third Affiliated Hospital of Sun Yat-Sen University

\section{Research Article}


Keywords: Fulminant hepatitis, Human umbilical cord-derived mesenchymal stem cells (hUC-MSCs), Immunomodulatory, Concanavalin A (Con A), NF-kB, Glycolysis

Posted Date: May 10th, 2021

DOl: https://doi.org/10.21203/rs.3.rs-494507/v1

License: (c) (1) This work is licensed under a Creative Commons Attribution 4.0 International License. Read Full License 


\section{Abstract}

Background: Fulminant hepatitis is a severe life-threatening clinical condition with rapid progressive loss of liver function. It is characterised by massive activation and infiltration of immune cells into the liver and disturbance of inflammatory cytokine production. Mesenchymal stem cells (MSCs) showed potent immunomodulatory properties, and transplantation of MSCs is suggested as a promising therapeutic approach for a host of inflammatory conditions.

Methods: In the current study, a well-established Concanavalin A (Con A)-induced fulminant hepatitis mouse model was used to investigate the effects of transplanting human umbilical cord MSC (hUC-MSC) on fulminant hepatitis.

Results: We showed that hUC-MSCs effectively alleviate fulminant hepatitis in mouse models, primarily through inhibiting T cell immunity. RNA-sequencing of liver tissues and human T cells co-cultured with hUC-MSCs showed that NF-KB signaling and glycolysis are two main pathways involved in mediating the protective role of hUC-MSCs on both Con A-induced hepatitis in vivo and T cell activation in vitro.

Conclusion: In summary, our data confirmed the potent therapeutic role of MSCs-derived from human umbilical cord on Con A-induced fulminant hepatitis, and uncovered new mechanisms that glycolysis metabolic shift mediates suppression of hUC-MSCs on T cell immunity.

\section{Introduction}

Fulminant hepatitis is an emergency clinical condition usually caused by hepatitis viral infection, or toxin (or drug) exposure that mediates rapid liver function destruction. It is an inflammatory lesion of the liver parenchymal mediated by the immune responses (1). No specific therapies are currently available for fulminant hepatitis, and orthotopic liver transplantation is the only definitive therapy for end-stage fulminant hepatitis patients. However, liver transplantation's practical application is limited by the desperate shortage of donor organs and high costs.

Mesenchymal stem cells (MSCs) are adult stem cells found in almost all tissues and organs $(2,3)$. These cells could accumulate at the sites of damage or inflammation and exhibit multipotency potential into various types of differentiated cells (4-6). Moreover, MSCs exhibited potent immunomodulatory functions both in vitro and in vivo, and thus demonstrated the therapeutic potential for many inflammatory disorders, such as acute graft-versus-host disease (aGVHD) (7), rheumatic arthritis (8), inflammatory bowel diseases (9), and so on. MSCs may modulate the immune responses through either direct cell-to-cell contact or paracrine secretion of soluble factors (10-14). The therapeutic potential of MSCs in the treatment of liver failure has been confirmed in both preclinical and clinical trials (15-17).

Concanavalin A (Con A)-induced fulminant liver injury is a well-documented murine model closelyresembling the pathological process of human viral hepatitis and autoimmune liver disease (18-21). Previous studies showed that bone marrow-derived MSCs (17, 22-28), tonsil-derived MSCs (29), and 
adipose tissue-derived MSCs (30-33) effectively protect mice from Con A-induced liver injury. However, the source of MSCs in all these tissues is quite limited, and isolating MSCs from these tissues is invasive. Human UC-MSCs isolated from the umbilical cord (which is considered waste material) provide an attractive MSCs source alternative. UC-MSCs share a similar morphology, surface markers, tri-lineage differentiation potential, and potent immunomodulatory properties with MSCs from other origins.

Moreover, there are sufficient sources, suitable materials, easy isolation and culture procedures, and no ethical or moral restrictions for utilising hUC-MSCs (34). These advantages make hUC-MSCs attractive for extensive studies in the field of stem cell-based therapy research recently.

In this study, the therapeutic effect of hUC-MSCs on Con A-induced fulminant liver injury was investigated, demonstrating that hUC-MSCs could efficiently alleviate Con A-induced liver injury. Mechanistically, hUC-MSCs suppress the hepatic T cell infiltration and activation by inhibiting NF-KB signaling and glycolysis. The results confirmed that hUC-MSCs transplantation is a potential therapeutic approach for treating fulminant hepatitis while uncovering new mechanisms for the immunomodulatory functions of hUC-MSCs.

\section{Materials And Methods}

\section{Animals}

C57BL/6J mice were purchased from Nanjing University Model Animals Institute (Nanjing, China) and housed under specific pathogen-free conditions. Experiments were performed with male animals at 6-8 weeks of age under ethical conditions approved by the Institutional Animal Care and Use Committee of The Third Affiliated Hospital of Sun Yat-sen University.

For Con A-induced fulminant hepatitis model, a single dose of Con A (Sigma Aldrich, St. Louis, MO) was administrated at 15 or $20 \mathrm{mg} / \mathrm{kg}$ (only for survival analysis) through the tail vein. PBS or $1 \times 10^{6} \mathrm{hUC}$ MSCs suspended in $200 \mu \mathrm{L}$ PBS were transplanted intravenously (i.v) 30 min after Con A administration. Liver tissues were collected 24 hours later, whereas serum was collected at various time points for further analysis.

\section{Isolation and culture of human UC-MSCs}

Human umbilical cord collection and processing were conducted after receiving informed consent from all participants included in the study. The hUC-MSCs were obtained and expanded as previously described with minor modifications (35). In summary, to isolate hUC-MSCs, the umbilical cord was dissected into short sections of about $3 \mathrm{~cm}$ in length, and the vessels were manually stripped. The Wharton's jelly was then separated from the umbilical cord and minced into small fragments with an approximate diameter of $2 \mathrm{~mm}$. The minced tissue was digested by collagenase for 1 hour and cultured in low glucose DMEM supplemented with 10\% heat-inactivated Fetal Bovine Serum (FBS), 2 mM L- 
glutamine and $1 \%$ Penicillin-Streptomycin at $37^{\circ} \mathrm{C}$ in a $5 \% \mathrm{CO}_{2}$ humidified incubator. The medium was changed every three days, and non-adherent cells were discarded by completely changing the medium. Fibroblast-like cells that were considered to be hUC-MSCs grew around the explants in about ten days. Adherent hUC-MSCs were detached using $0.125 \%$ Trypsin-EDTA and passaged at a split ratio of 1:3 when they reached $80-90 \%$ confluence. All of the hUC-MSCs used in this study were characterised by flow cytometry and multi-directional differentiation. This study was approved by the Institutional Human Ethics Committee of The Third Affiliated Hospital of Sun Yat-sen University.

\section{Differentiation of hUC-MSCs to osteoblasts and adipocytes}

For differentiation to osteoblasts, hUC-MSCs were seeded onto a 6-well plate at a density of $4 \times 10^{3} / \mathrm{cm}^{2}$. After the cells reached $60-70 \%$ confluence, the medium was replaced with osteoblast induction medium containing L-DMEM, 10\% (v/v) FBS, 2 mM glutamine, 1\% Penicillin-Streptomycin, dexamethasone (0.1 $\mu \mathrm{M}$, Merck), Vitamin C (50 $\mu \mathrm{g} / \mathrm{mL}$, Sigma-Aldrich) and $\beta$-glycerol phosphate (10 mM, Sigma-Aldrich). The medium was replaced every three days, monitoring to note cell growth and morphological changes. After three weeks of induction, osteogenic differentiation was confirmed by staining with $0.5 \%$ Alizarin Red S (v/v) (Sigma-Aldrich). For differentiation to adipocytes, hUC-MSCs were seeded onto a 6-well plate at a density of $4 \times 10^{3} / \mathrm{cm}^{2}$. After the cells reached $80-90 \%$ confluence, the medium was replaced with an adipogenic induction medium containing H-DMEM, 10\% (v/v) FBS, 2 mM glutamine, 1\% PenicillinStreptomycin, dexamethasone (1 $\mu \mathrm{M}$, Merck), insulin (10 $\mathrm{g} / \mathrm{mL}$, Prospect), isobutylmethylxanthine (IBMX, 0.5 mM, Sigma-Aldrich) and indomethacin (0.2 mM, Sigma-Aldrich). The medium was replaced every three days, monitoring to note cell growth and morphological changes. After the typical lipid droplets' appearance, adipogenic differentiation was confirmed by staining with Oil Red 0 (00625, SigmaAldrich).

\section{Flow cytometry and cell sorting}

Cells were washed and stained with labeled antibody (or isotype control) according to the manufacturer's instructions. Flow cytometric analysis was performed on either an LSR II (BD) or CytoFLEX flow cytometer (Beckman Coulter, Fullerton, CA, USA), and the data were analysed with FlowJo7.6 software (Treestar, Ashland, OR, USA). For flow cytometric cell sorting, cells were stained with the appropriate antibodies and isolated on a BD influx cell sorter (BD Biosciences, USA).

\section{Co-culture of hUC-MSCs with T cells and the proliferation assay}

First, human peripheral blood mononuclear cells $\triangle P B M C \unrhd$ were isolated by density gradient centrifugation. The T lymphocytes were then stained with CD3-FITC and sorted on a BD influx cell sorter (BD 
Biosciences, USA). For co-culture, hUC-MSCs were seeded in a 24-well plate and co-cultured at the ratio of hUC-MSCs: $\mathrm{CD}^{+} \mathrm{T}$ cell $=1: 5$. The stimulant was phytohaemagglutinin (PHA, Sigma-Aldrich) at a final concentration of $2.5 \mu \mathrm{g} / \mathrm{mL}$. Following co-culture for 48 hours, $\mathrm{CD}^{+} \mathrm{T}$ cells that were stimulated separately and the $\mathrm{CD}^{+}$cells co-cultured with hUC-MSCs were collected and analyzed using flow cytometry (CytoFLEX, Beckman Coulter).

\section{Hematoxylin and eosin (H\&E) staining}

Mouse liver tissues at the equivalent locations were fixed in 4\% paraformaldehyde overnight and embedded in paraffin. Sections of $4 \mu \mathrm{m}$ were prepared for H\&E staining.

\section{Serum alanine aminotransferase (ALT) and Aspartate Transaminase (AST) measurements}

Mouse blood was sampled at various time points after Con A administration and then centrifuged at $3000 \mathrm{rpm}$ at $4^{\circ} \mathrm{C}$ for $15 \mathrm{~min}$ to separate the serum. ALT and AST levels were measured using a Hitachi 7020 automatic biochemical analyzer (Hitachi, Tokyo, Japan).

\section{Isolation of liver non-parenchymal cells}

Mouse liver tissues were collected and perfused with Collagenase I to dissociate cells, followed by filtration through a $200 \mu \mathrm{M}$ cell strainer. Hepatocytes were removed by centrifuging at $50 \mathrm{~g}$ for three min at $4^{\circ} \mathrm{C}$. Supernatants were collected and liver non-parenchymal cells were isolated with mouse lymphocytes separation medium (tdbscience, China).

\section{RNA sequencing}

The sample preparation, sequencing, and data analysis were performed as previously described (36). GSEA was conducted using the Gene set enrichment analysis (GSEA) software (https://www.broadinstitute.org/gsea/) (37). Differentially expressed genes (DEGs) were identified using DESeq2 (38) on the following cutoff criteria: $\mathrm{P}<0.05$ and $|\mathrm{FC}|>1.5$. GO and KEGG pathway analyses of the DEGs were performed using the online Database for Annotation Visualization and Integrated Discovery (DAVID) (https://david. ncifcrf.gov/), with $\mathrm{P}<0.05$ as the threshold for statistical significance. Sequencing data are available in the Gene Expression Omnibus (GEO) database under the accession number GSE166327.

\section{Statistical analysis}


All results were expressed as mean \pm SD. Statistical comparison was made using the two-tailed Student's $t$-test between two groups or one-way ANOVA for multi-group comparison. Survival was analyzed by the Kaplan-Meier log-rank test. $\mathrm{P}<0.05$ was considered significant. Analyses and graphs were performed using GraphPad Prism version 7 (San Diego, CA).

\section{Results}

\section{hUC-MSCs effectively protected mice from Con A-induced fulminant hepatitis}

Like MSCs of other origins and previous reports $(2,3)$, hUC-MSCs were strongly positive for CD29, CD73, CD105, and CD90, whereas they were negative for hematopoietic stem cell markers such CD34 and CD45 (Supplementary Figure 1A). The cells showed typical spindle-shaped fibroblastic morphology (Supplementary Figure 1B) and were successfully induced to differentiate into osteoblasts and adipocytes (Supplementary Figure 1C).

To evaluate the therapeutic effects of hUC-MSCs on Con A-induced fulminant hepatitis, fulminant liver failure was induced using Con A (20 mg/kg) in mice, and either PBS or hUC-MSCs was administered intravenously 0.5 hours later (Figure 1A). Compared with the PBS group, hUC-MSCs demonstrated significant protection on Con A-induced death (Figure 1B). A sub-lethal dose of Con A (15 mg/kg) was then administrated to study the mechanism of hUC-MSCs mediated protection on Con A-induced liver injury. The hUC-MSCs group showed significantly decreased serum ALT and AST activity (two liver injury markers) at 6, 12, 24, and 48 hours after Con A administration, indicating and immediate, effective improvement of Con A-induced liver injury by hUC-MSCs (Figure 1C and 1D). Observation of gross liver specimens and histological analysis at 24 hours showed that hUC-MSCs effectively ameliorated Con Ainduced hepatocyte necrosis and disseminated hemorrhage (Figure 1E and 1F). These results confirm that hUC-MSCs effectively protected the mouse liver from Con A-induced liver injury in vivo.

\section{hUC-MSCs suppressed the activation of $\mathrm{CD}^{+}$hepatic T cells in Con A-induced fulminant hepatitis}

The Con A-induced liver injury model is characterised by lymphocyte-induced liver damage, especially $\mathrm{CD} 4^{+} \mathrm{T}$ lymphocytes activation and infiltration in the liver (39). Therefore, this model is considered a suitable mouse model for studying the pathological mechanisms of liver damage due to, for example, human viral hepatitis and autoimmune liver disease (18). However, activation of other immune cells (including B cells, macrophages, NK cells, and NKT cells) has also contributed to Con A-induced hepatitis $(19,40-42)$. To determine which immune cells hUC-MSCs modulate in the liver, liver non-parenchymal cells of control, Con A + PBS group and Con A + hUC-MSCs group were isolated 24 hours after Con A administration. A flow cytometry analysis was undertaken to determine which subpopulations were 
changed by the hUC-MSCs (Figure $2 \mathrm{~A}$ ). The results showed that the number of $\mathrm{CD}^{+} \mathrm{T}$ cells and $\mathrm{F} 4 / 80+$

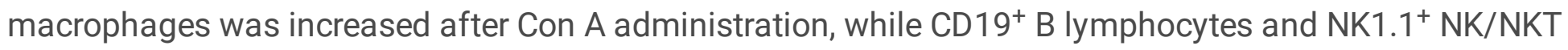
cells were decreased (Figure 2B). However, only the $\mathrm{CD} 3^{+} \mathrm{T}$ cell (especially $\mathrm{CD} 3^{+} \mathrm{CD} 4^{+} \mathrm{T}$ cells) ratio recovered after the treatment with hUC-MSCs (Figure 2B and 2C). These results infer that hUC-MSCs alleviate Con A-induced hepatitis primarily through suppressing hepatic CD3+ $T$ cells.

\section{Transcriptional analysis of hUC-MSCs mechanisms to alleviate Con A-induced fulminant hepatitis in vivo}

The RNA-sequencing for liver tissues of the control group, Con A + PBS group, and Con A + hUC-MSCs group 24 hours after Con $A$ administration were determined, to further characterise the mechanisms via which hUC-MSCs alleviate Con A-induced hepatitis (Supplementary Table 1). Gene set enrichment analysis (GSEA) showed that almost all (35/36) pathways significantly changed in the Con A + PBS group versus the control group were recovered in the Con A + hUC-MSCs group (Figure 3A). We found that crucial liver functions, such as bile acid metabolism, xenobiotic metabolism, and fatty acid metabolism, were repressed in the Con A + PBS group and reconstituted in the Con A + hUC-MSCs group (Figure 3B3D). Also, inflammatory response pathways including IL-2-STAT5, TNFa signaling via NF-KB, IFNa, and IFNY response were among the most significantly enriched gene pathways in the Con A + PBS group. They were repressed in the Con A + hUC-MSCs group (Figure 3B, 3E). Consistent with the phenomenon of massive hepatocyte necrosis and activation of immune cells, apoptosis pathway and cell cycle-related pathways (including E2F targets, G2M checkpoints, and Myc targets) were activated in the Con A + PBS group (Supplementary Figure 2A and $2 \mathrm{~B}$ ). Both pathways returned to the resting state in the Con $\mathrm{A}+\mathrm{hUC}$ MSCs group (Supplementary Figure 2A and 2B), consistent with the observation of decreased hepatocyte necrosis (Figure 1F) and suppressed T cell infiltration in the liver (Figure 2B) after hUC-MSCs treatment. Notably, we also observed a significant change in other metabolism pathways, including activation of glycolysis, mTORC1, and hypoxia response after Con A administration and corresponding recovery following hUC-MSCs infusion. The oxidative phosphorylation pathways showed the opposite tendency (Figure 3F, Supplementary Figure 2C). In total, 562/674 upregulated and 546/726 downregulated genes in Con A + hUC-MSCs group compared to Con A + PBS group showed opposite expression tendencies in the Con A + PBS group versus the control group (Supplementary Figure 2D and 2E), demonstrating significant molecular changes following hUC-MSC treatment. GO and KEGG pathway analysis of differentially expressed genes (DEGs) showed similar results to the GSEA analysis, confirming metabolism and inflammatory pathways are the primary pathways mediating the therapeutic effects of hUC-MSCs on Con A-induced hepatitis (Supplementary Figure 3 and 4).

\section{Bioinformatics analysis of hUC-MSCs mechanisms to inhibit the activation and proliferation of T cells in vitro}


Since Con A-induced fulminant hepatitis is mainly T cell-mediated hepatic injury, treatment with hUCMSCs could ameliorate Con A-induced liver injury principally by reducing $\mathrm{CD}^{+} \mathrm{T}$ cell infiltration (Figure 2B). To further investigate the mechanisms by which hUC-MSCs function, we performed RNA-sequencing analysis of naïve T cells, activated T cells, and activated T cells co-cultured with hUC-MSCs (Supplementary Table 2). Like liver tissues, most (28/31) of the significantly enriched pathways comparing $T$ cells versus activated $T$ cells were recovered, compared to activated $T$ cells versus activated T cells co-cultured with hUC-MSCs (Figure 4A), indicating a strong suppression of T cell immunity by hUCMSCs. GSEA analysis showed that similar to Con A-induced liver injury models, inflammatory pathways, such as IL-2-STAT5, TNFa signaling via NF-KB (Figure 4B and C), cell cycle-related pathways (Supplementary Figure 5A), and metabolism pathways (including glucose metabolic process, hypoxia, and mTORC1 signaling) (Figure 4D, Supplementary Figure 5B) were enriched in activated T cells and repressed in activated T cells co-cultured with hUC-MSCs. Interestingly, unlike in liver tissues, oxidative phosphorylation pathways were activated in activated T cells (Supplementary Figure 5C), consistent with previous reports that both aerobic glycolysis and oxidative phosphorylation were increased in activated T cells (43). Most of the differentially regulated genes after $\mathrm{T}$ cell activation recovered in activated $\mathrm{T}$ cells co-cultured with hUC-MSCs (Figure 4E and 4F). The KEGG pathway analysis of these differentially regulated genes confirmed significant metabolic changes among all three groups (Supplementary Figure $5 \mathrm{D})$.

\section{NF-KB signaling and glycolysis are shared pathways between the in vivo and in vitro models}

The overlapped genes of the four categories were considered and analysed: 1) downregulated in Con A+ hUC-MSCs versus Con A + PBS group, 2) upregulated in Con A + PBS versus control group, 3) downregulated in activated T cells co-cultured with hUC-MSCs versus activated T cells and 4) upregulated in activated T cells versus naïve T cells. Eighty-nine genes met the criteria, and the KEGG pathway analysis showed that the NF-KB signaling pathway, HIF-1a signaling, and glycolysis pathways were among the most significantly enriched pathways (Figure 5A). Key genes involved in NF-kB signaling and glycolysis were upregulated in Con A-treated mouse liver tissues and activated human $\mathrm{T}$ cells, while all were repressed following treatment with hUC-MSCs. As HIF-1a signaling could directly induce glycolysis under hypoxic conditions $(44,45)$, these results confirm that NF-KB signaling and glycolysis metabolic processes are two important pathways mediating the therapeutic function of hUC-MSCs both in Con A-induced fulminant hepatitis in vivo and $T$ cell activation in vitro (Figure 5B and $5 C$ ). RT-qPCR analysis of liver tissues confirmed that Con A administration indeed induced key enzymes involved in glycolysis and MSC treatment partially blunted this effect (Figure 5D).

\section{Discussion}

MSCs are a heterogeneous population of fibroblast-like progenitor cells derived from mesoderm and ectoderm in early development. Their multidirectional differentiation potential, ease of isolation and gene 
modification, low immunogenicity, chemotaxis to damaged tissues, potent immunoregulatory functions, and many other advantages infer that MSCs have tremendous unrealised potential in cell therapy and regenerative medicine $(5,46-49)$. MSCs can be derived from bone marrow, umbilical cord, amniotic fluid, placenta, muscle, adipose tissues, dermis, liver, and almost all tissues and organs $(2,3)$. Since the isolation of MSCs, most preclinical and clinical studies utilised bone-marrow MSCs for cell therapy. Sources of bone marrow-derived MSCs are quite limited, and the isolation procedure is invasive. In the present study, human umbilical cord-derived MSCs were used to treat fulminant hepatitis. The hUC-MSCs are rapidly isolated in large numbers from Wharton's jelly of the umbilical cord, which is considered medical waste, providing a robust and efficient source for MSC cell therapy. The current study confirmed that hUC-MSCs have significant therapeutic effects on Con A-induced fulminant hepatitis in vivo and potently inhibit T cell immunity in vitro and are as functional as MSCs from other origins $(27,29,30)$.

Concanavalin A (Con A) is a plant lectin extracted from Brazilian rubber Canavalia. Con A-induced liver injury is a commonly used murine liver injury model considered suitable for studying the pathological mechanisms of human viral hepatitis and autoimmune liver disease. The changes in hemodynamics, morphology, and biochemical metabolism are similar to human viral hepatitis and autoimmune liver disease, etc. In Con A-induced liver injury, lymphocyte (especially CD $4^{+} \mathrm{T}$ cell) activation and infiltration play a central role in inducing liver damage $(18,19,40,42,50-52)$. Con A can activate many macrophages in the liver sinusoid to produce cytokines, directly damaging liver cells (53), or activate $T$ lymphocytes to produce cytokines and infiltrate the liver leading to immune liver damage (54). Several studies previously reported that MSCs from different origins could alleviate Con A-induced hepatitis by acting on different types of immune cells, including switching Con A-stimulated macrophages to the M2 phenotype by bone marrow-derived MSCs (27), suppression of myeloid-lineage cells and $\mathrm{CD} 4^{+} \mathrm{T}$ cell by adipose-derived MSCs (30), suppression of T cells by both bone marrow-derived MSCs and tonsil-derived MSCs $(26,29)$, and suppression of NKT cells by bone marrow-derived MSCs $(24,28)$. Interestingly, our results demonstrated that hUC-MSCs alleviate Con A-induced fulminant hepatitis primarily by suppressing hepatic $\mathrm{CD}^{+} \mathrm{T}$ cells with no significant change of macrophages, $\mathrm{CD} 19^{+} \mathrm{B}$ lymphocytes and NK1.1 ${ }^{+}$NK/NKT cells. These results indicated that MSCs from different origins might exert therapeutic outcomes through several disparate mechanisms.

To further elucidate the regulatory mechanisms by which hUC-MSCs protect Con A-induced fulminant hepatitis, RNA-sequencing analysis of liver tissues was undertaken. As expected, noticeable improvement in liver functions was observed following hUC-MSCs treatment, such as fatty acid metabolism, bile acid metabolism and xenobiotic metabolism. Furthermore, inflammatory response and cell cycle-related pathways were significantly inhibited by hUC-MSCs administration. Interestingly, we also observed the induction of glycolysis by Con A and its suppression after hUC-MSCs administration. Notably, the changes of inflammatory response pathway, cell cycle-related pathway, and glycolysis were recapitulated in T cells activated in vitro and co-cultured with hUC-MSCs.

Analysis of merged DEGs in mouse liver tissues and human T cells showed that NF-KB signaling and glycolysis were two critical pathways mediating the therapeutic function of hUC-MSCs both in Con A- 
induced fulminant hepatitis in vivo and T cell activation in vitro. NF-KB is a common inflammatory signaling pathway, previously reported to be activated in Con A-induced fulminant hepatitis and suppressed by MSCs (25). Glycolysis plays an essential role in T cell immunity (55-59). However, to the best of our knowledge, no previous studies have detailed the involvement of glycolysis in Con A-induced liver injury. Additionally, few studies reported MSCs modulating glycolysis in target cells/tissues (60). Our data showed that glycolysis is upregulated in Con A-treated mouse liver tissues and activated human T cells. Simultaneously, glycoysis is repressed following treatment with hUC-MSCs in both systems, indicating that glycolysis plays an important role in mediating the therapeutic outcomes of hUC-MSCs. Further investigations are warranted to see whether targeting glycolysis with other therapeutics will alleviate Con A-induced fulminant hepatitis. Equally of interest are future studies to determine whether hUC-MSCs could mitigate other T cell-mediated tissue injuries by inhibiting glycolysis.

\section{Conclusion}

In this study, we confirmed the potent therapeutic role of MSCs-derived from human umbilical cord on Con A-induced fulminant hepatitis, and uncovered new mechanisms that glycolysis metabolic shift mediates suppression of hUC-MSCs on T cell immunity.

\section{Abbreviations}

aGVHD: acute graft-versus-host disease; ALT: Alanine aminotransferase; AST: Aspartate transaminase; Con A: Concanavalin A; DAVID: Database for annotation visualization and integrated discovery; DEG: Differentially expressed genes; FBS: Fetal Bovine Serum; GEO: Gene expression omnibus; GO: Gene ontology; GSEA: Gene set enrichment analysis; H\&E: Hematoxylin and eosin; hUC-MSCs: human umbilical cord MSCs; IBMX: Isobutylmethylxanthine; KEGG: Kyoto encyclopaedia of genes and genomes; MSCs: Mesenchymal stem cells; PBMC: Peripheral blood mononuclear cells; PHA: Phytohaemagglutinin

\section{Declarations}

\section{Acknowledgments}

We show our full respect and gratitude to all members from Qi Zhang and Yan Xu's lab for their discussion and technical assistance.

\section{Authors' Contributions}

Qi Zhang and Yan Xu conceived the idea, supervised the study, and analyzed data. Chang Liu and Yan Xu wrote the manuscript with the help of Lijie Pan and Qiuli Liu. Lijie Pan, Chang Liu and Qiuli Liu conducted most experiments with the help of Yanli Li, Cong Du, Xinmei Kang, Shuai Dong, Zhuowei Zhou, Huaxin Chen, Xiaoqi Liang, Jiajie Chu. The manuscript was read and approved by all authors. 


\section{Funding}

This work was supported by the National Key Research and Development Program of China (2017YFA0106100), National Natural Science Foundation of China (31601184 and 81970537) and Guangdong Basic and Applied Basic Research Foundation (2020A1515011385).

\section{Availability of data and materials}

All data will be made available upon reasonable request to the corresponding author.

\section{Ethics approval and consent to participate}

Animal experiments in this study were conducted under ethical conditions approved by the Institutional Animal Care and Use Committee of The Third Affiliated Hospital of Sun Yat-sen University. Isolation and expansion of hUC-MSCs were approved by the Institutional Human Ethics Committee of The Third Affiliated Hospital of Sun Yat-sen University.

\section{Consent for publication}

Not applicable.

\section{Competing interests}

All authors declare no competing interests.

\section{References}

1. Ichai P, Samuel D. Etiology and prognosis of fulminant hepatitis in adults. Liver Transpl. 2008;14 Suppl 2:S67-79.

2. Kern S, Eichler H, Stoeve J, Kluter H, Bieback K. Comparative analysis of mesenchymal stem cells from bone marrow, umbilical cord blood, or adipose tissue. Stem Cells. 2006;24(5):1294-301.

3. Campagnoli C, Roberts IA, Kumar S, Bennett PR, Bellantuono I, Fisk NM. Identification of mesenchymal stem/progenitor cells in human first-trimester fetal blood, liver, and bone marrow. Blood. 2001;98(8):2396-402.

4. Antony AK, Rodby K, Tobin MK, O'Connor MI, Pearl RK, DiPietro LA, et al. Composite tissue allotransplantation and dysregulation in tissue repair and regeneration: a role for mesenchymal stem cells. Front Immunol. 2013;4:188. 
5. De Becker A, Riet IV. Homing and migration of mesenchymal stromal cells: How to improve the efficacy of cell therapy? World J Stem Cells. 2016;8(3):73-87.

6. Singer NG, Caplan Al. Mesenchymal stem cells: mechanisms of inflammation. Annu Rev Pathol. 2011;6:457-78.

7. Peng Y, Chen X, Liu Q, Zhang X, Huang K, Liu L, et al. Mesenchymal stromal cells infusions improve refractory chronic graft versus host disease through an increase of CD5+ regulatory B cells producing interleukin 10. Leukemia. 2015;29(3):636-46.

8. Ghoryani M, Shariati-Sarabi Z, Tavakkol-Afshari J, Mohammadi M. The Sufficient Immunoregulatory Effect of Autologous Bone Marrow-Derived Mesenchymal Stem Cell Transplantation on Regulatory T Cells in Patients with Refractory Rheumatoid Arthritis. J Immunol Res. 2020;2020:3562753.

9. Lightner AL, Dozois EJ, Dietz AB, Fletcher JG, Friton J, Butler G, et al. Matrix-Delivered Autologous Mesenchymal Stem Cell Therapy for Refractory Rectovaginal Crohn's Fistulas. Inflamm Bowel Dis. 2020;26(5):670-7.

10. Bulati M, Miceli V, Gallo A, Amico G, Carcione C, Pampalone M, et al. The Immunomodulatory Properties of the Human Amnion-Derived Mesenchymal Stromal/Stem Cells Are Induced by INFgamma Produced by Activated Lymphomonocytes and Are Mediated by Cell-To-Cell Contact and Soluble Factors. Front Immunol. 2020;11:54.

11. Poggi A, Zocchi MR. Immunomodulatory Properties of Mesenchymal Stromal Cells: Still Unresolved "Yin and Yang". Curr Stem Cell Res Ther. 2019;14(4):344-50.

12. Shi Y, Wang Y, Li Q, Liu K, Hou J, Shao C, et al. Immunoregulatory mechanisms of mesenchymal stem and stromal cells in inflammatory diseases. Nat Rev Nephrol. 2018;14(8):493-507.

13. Ren G, Zhang L, Zhao X, Xu G, Zhang Y, Roberts Al, et al. Mesenchymal stem cell-mediated immunosuppression occurs via concerted action of chemokines and nitric oxide. Cell Stem Cell. 2008;2(2):141-50.

14. Soleymaninejadian E, Pramanik K, Samadian E. Immunomodulatory properties of mesenchymal stem cells: cytokines and factors. Am J Reprod Immunol. 2012;67(1):1-8.

15. Lin BL, Chen JF, Qiu WH, Wang KW, Xie DY, Chen XY, et al. Allogeneic bone marrow-derived mesenchymal stromal cells for hepatitis $B$ virus-related acute-on-chronic liver failure: A randomized controlled trial. Hepatology. 2017;66(1):209-19.

16. Shi M, Zhang Z, Xu R, Lin H, Fu J, Zou Z, et al. Human mesenchymal stem cell transfusion is safe and improves liver function in acute-on-chronic liver failure patients. Stem Cells Transl Med. 2012;1(10):725-31.

17. Sun K, Xie X, Xie J, Jiao S, Chen X, Zhao X, et al. Cell-based therapy for acute and chronic liver failures: distinct diseases, different choices. Sci Rep. 2014;4:6494.

18. Tiegs $\mathrm{G}$, Hentschel J, Wendel A. A T cell-dependent experimental liver injury in mice inducible by concanavalin A. J Clin Invest. 1992;90(1):196-203.

19. Kusters S, Gantner F, Kunstle G, Tiegs G. Interferon gamma plays a critical role in T cell-dependent liver injury in mice initiated by concanavalin A. Gastroenterology. 1996;111(2):462-71. 
20. Heymann F, Hamesch K, Weiskirchen R, Tacke F. The concanavalin A model of acute hepatitis in mice. Lab Anim. 2015;49(1 Suppl):12-20.

21. Ye $T$, Wang $T$, Yang $X$, Fan $X$, Wen $M$, Shen $Y$, et al. Comparison of Concanavalin a-Induced Murine Autoimmune Hepatitis Models. Cell Physiol Biochem. 2018;46(3):1241-51.

22. Zhou L, Liu S, Wang Z, Yao J, Cao W, Chen S, et al. Bone Marrow-Derived Mesenchymal Stem Cells Modified with Akt1 Ameliorates Acute Liver GVHD. Biol Proced Online. 2019;21:24.

23. Tamura R, Uemoto $S$, Tabata Y. Immunosuppressive effect of mesenchymal stem cell-derived exosomes on a concanavalin A-induced liver injury model. Inflamm Regen. 2016;36:26.

24. Zhu X, He B, Zhou X, Ren J. Effects of transplanted bone-marrow-derived mesenchymal stem cells in animal models of acute hepatitis. Cell Tissue Res. 2013;351(3):477-86.

25. Gu Y, Ding X, Huang J, Xue M, Zhang J, Wang Q, et al. The deubiquitinating enzyme UCHL1 negatively regulates the immunosuppressive capacity and survival of multipotent mesenchymal stromal cells. Cell Death Dis. 2018;9(5):459.

26. Han X, Yang Q, Lin L, Xu C, Zheng C, Chen X, et al. Interleukin-17 enhances immunosuppression by mesenchymal stem cells. Cell Death Differ. 2014;21(11):1758-68.

27. Lee KC, Lin HC, Huang YH, Hung SC. Allo-transplantation of mesenchymal stem cells attenuates hepatic injury through IL1Ra dependent macrophage switch in a mouse model of liver disease. J Hepatol. 2015;63(6):1405-12.

28. Gazdic M, Simovic Markovic B, Vucicevic L, Nikolic T, Djonov V, Arsenijevic N, et al. Mesenchymal stem cells protect from acute liver injury by attenuating hepatotoxicity of liver natural killer $\mathrm{T}$ cells in an inducible nitric oxide synthase- and indoleamine 2,3-dioxygenase-dependent manner. J Tissue Eng Regen Med. 2018;12(2):e1173-e85.

29. Ryu KH, Kim SY, Kim YR, Woo SY, Sung SH, Kim HS, et al. Tonsil-derived mesenchymal stem cells alleviate concanavalin A-induced acute liver injury. Exp Cell Res. 2014;326(1):143-54.

30. Higashimoto M, Sakai Y, Takamura M, Usui S, Nasti A, Yoshida K, et al. Adipose tissue derived stromal stem cell therapy in murine ConA-derived hepatitis is dependent on myeloid-lineage and CD4+ T-cell suppression. Eur J Immunol. 2013;43(11):2956-68.

31. Kubo N, Narumi S, Kijima H, Mizukami H, Yagihashi S, Hakamada K, et al. Efficacy of adipose tissuederived mesenchymal stem cells for fulminant hepatitis in mice induced by concanavalin A. J Gastroenterol Hepatol. 2012;27(1):165-72.

32. Nasti A, Sakai Y, Seki A, Buffa GB, Komura T, Mochida H, et al. The CD45(+) fraction in murine adipose tissue derived stromal cells harbors immune-inhibitory inflammatory cells. Eur $\mathrm{J}$ Immunol. 2017;47(12):2163-74.

33. Wang W, Guo H, Li H, Yan Y, Wu C, Wang X, et al. Interleukin-35 Gene-Modified Mesenchymal Stem Cells Protect Concanavalin A-Induced Fulminant Hepatitis by Decreasing the Interferon Gamma Level. Hum Gene Ther. 2018;29(2):234-41.

34. Weiss ML, Anderson C, Medicetty S, Seshareddy KB, Weiss RJ, VanderWerff I, et al. Immune properties of human umbilical cord Wharton's jelly-derived cells. Stem Cells. 2008;26(11):2865-74. 
35. Weiss ML, Medicetty S, Bledsoe AR, Rachakatla RS, Choi M, Merchav S, et al. Human umbilical cord matrix stem cells: preliminary characterization and effect of transplantation in a rodent model of Parkinson's disease. Stem Cells. 2006;24(3):781-92.

36. Zhuang Q, Li W, Benda C, Huang Z, Ahmed T, Liu P, et al. NCoR/SMRT co-repressors cooperate with cMYC to create an epigenetic barrier to somatic cell reprogramming. Nat Cell Biol. 2018;20(4):400-12.

37. Subramanian A, Tamayo P, Mootha VK, Mukherjee S, Ebert BL, Gillette MA, et al. Gene set enrichment analysis: a knowledge-based approach for interpreting genome-wide expression profiles. Proc Natl Acad Sci U S A. 2005;102(43):15545-50.

38. Love MI, Huber W, Anders S. Moderated estimation of fold change and dispersion for RNA-seq data with DESeq2. Genome Biol. 2014;15(12):550.

39. Hong F, Jaruga B, Kim WH, Radaeva S, El-Assal ON, Tian Z, et al. Opposing roles of STAT1 and STAT3 in T cell-mediated hepatitis: regulation by SOCS. J Clin Invest. 2002;110(10):1503-13.

40. Erhardt A, Biburger M, Papadopoulos T, Tiegs G. IL-10, regulatory T cells, and Kupffer cells mediate tolerance in concanavalin A-induced liver injury in mice. Hepatology. 2007;45(2):475-85.

41. Schumann J, Wolf D, Pahl A, Brune K, Papadopoulos T, van Rooijen N, et al. Importance of Kupffer cells for T-cell-dependent liver injury in mice. Am J Pathol. 2000;157(5):1671-83.

42. Takeda K, Hayakawa Y, Van Kaer L, Matsuda H, Yagita H, Okumura K. Critical contribution of liver natural killer T cells to a murine model of hepatitis. Proc Natl Acad Sci U S A. 2000;97(10):5498-503.

43. Chang CH, Curtis JD, Maggi LB, Jr., Faubert B, Villarino AV, O'Sullivan D, et al. Posttranscriptional control of T cell effector function by aerobic glycolysis. Cell. 2013;153(6):1239-51.

44. Codo AC, Davanzo GG, Monteiro LB, de Souza GF, Muraro SP, Virgilio-da-Silva JV, et al. Elevated Glucose Levels Favor SARS-CoV-2 Infection and Monocyte Response through a HIF1alpha/Glycolysis-Dependent Axis. Cell Metab. 2020;32(3):437-46 e5.

45. Cheng SC, Quintin J, Cramer RA, Shepardson KM, Saeed S, Kumar V, et al. mTOR- and HIF-1alphamediated aerobic glycolysis as metabolic basis for trained immunity. Science. 2014;345(6204):1250684.

46. Pittenger MF, Mackay AM, Beck SC, Jaiswal RK, Douglas R, Mosca JD, et al. Multilineage potential of adult human mesenchymal stem cells. Science. 1999;284(5411):143-7.

47. Le Blanc K, Mougiakakos D. Multipotent mesenchymal stromal cells and the innate immune system. Nat Rev Immunol. 2012;12(5):383-96.

48. Uccelli A, Moretta L, Pistoia V. Mesenchymal stem cells in health and disease. Nat Rev Immunol. 2008;8(9):726-36.

49. Galipeau J, Sensebe L. Mesenchymal Stromal Cells: Clinical Challenges and Therapeutic Opportunities. Cell Stem Cell. 2018;22(6):824-33.

50. Kaneko Y, Harada M, Kawano T, Yamashita M, Shibata Y, Gejyo F, et al. Augmentation of Valpha14 NKT cell-mediated cytotoxicity by interleukin 4 in an autocrine mechanism resulting in the development of concanavalin A-induced hepatitis. J Exp Med. 2000;191(1):105-14. 
51. Lohse AW, Dienes HP, Meyer zum Buschenfelde KH. Suppression of murine experimental autoimmune hepatitis by T-cell vaccination or immunosuppression. Hepatology. 1998;27(6):1536-43.

52. Wang HX, Liu M, Weng SY, Li JJ, Xie C, He HL, et al. Immune mechanisms of Concanavalin A model of autoimmune hepatitis. World J Gastroenterol. 2012;18(2):119-25.

53. Knolle PA, Gerken G, Loser E, Dienes HP, Gantner F, Tiegs G, et al. Role of sinusoidal endothelial cells of the liver in concanavalin A-induced hepatic injury in mice. Hepatology. 1996;24(4):824-9.

54. Louis H, Le Moine O, Peny MO, Quertinmont E, Fokan D, Goldman M, et al. Production and role of interleukin-10 in concanavalin A-induced hepatitis in mice. Hepatology. 1997;25(6):1382-9.

55. Lawless SJ, Kedia-Mehta N, Walls JF, McGarrigle R, Convery O, Sinclair LV, et al. Glucose represses dendritic cell-induced T cell responses. Nat Commun. 2017;8:15620.

56. Kunkl M, Sambucci M, Ruggieri S, Amormino C, Tortorella C, Gasperini C, et al. CD28 Autonomous Signaling Up-Regulates C-Myc Expression and Promotes Glycolysis Enabling Inflammatory T Cell Responses in Multiple Sclerosis. Cells. 2019;8(6).

57. Li Q, Yan Y, Liu J, Huang X, Zhang X, Kirschning C, et al. Toll-Like Receptor 7 Activation Enhances CD8+ T Cell Effector Functions by Promoting Cellular Glycolysis. Front Immunol. 2019;10:2191.

58. Ma EH, Verway MJ, Johnson RM, Roy DG, Steadman M, Hayes S, et al. Metabolic Profiling Using Stable Isotope Tracing Reveals Distinct Patterns of Glucose Utilization by Physiologically Activated CD8(+) T Cells. Immunity. 2019;51(5):856-70 e5.

59. Yi HS, Kim SY, Kim JT, Lee YS, Moon JS, Kim M, et al. T-cell senescence contributes to abnormal glucose homeostasis in humans and mice. Cell Death Dis. 2019;10(3):249.

60. Bottcher M, Hofmann AD, Bruns H, Haibach M, Loschinski R, Saul D, et al. Mesenchymal Stromal Cells Disrupt mTOR-Signaling and Aerobic Glycolysis During T-Cell Activation. Stem Cells. 2016;34(2):516-21.

\section{Figures}


B

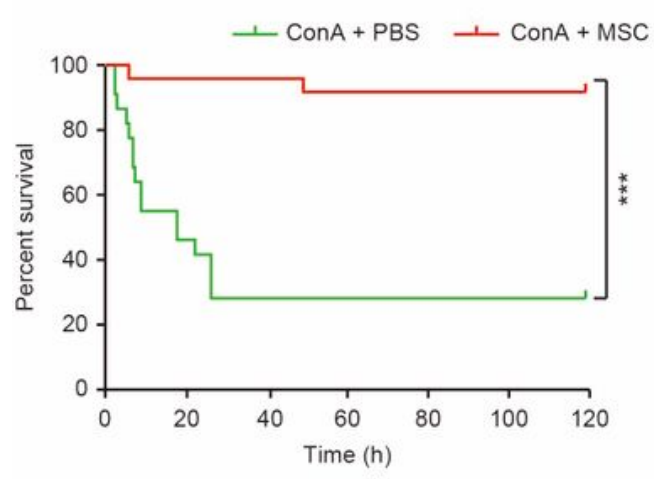

C

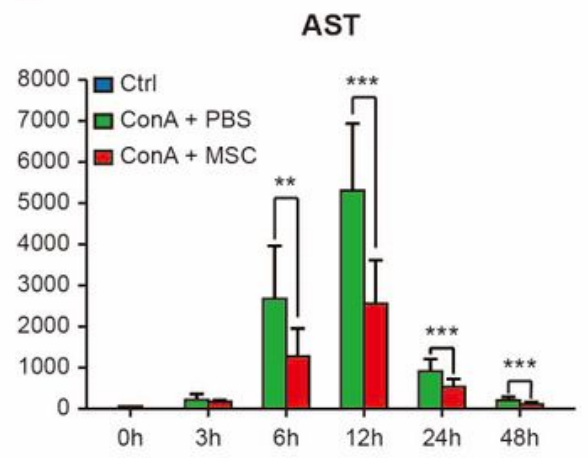

D

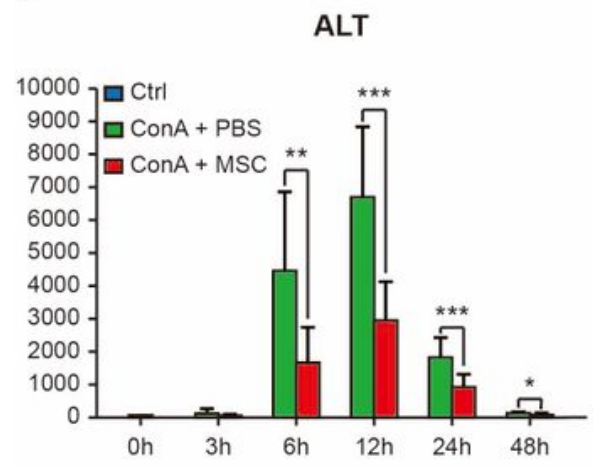

F
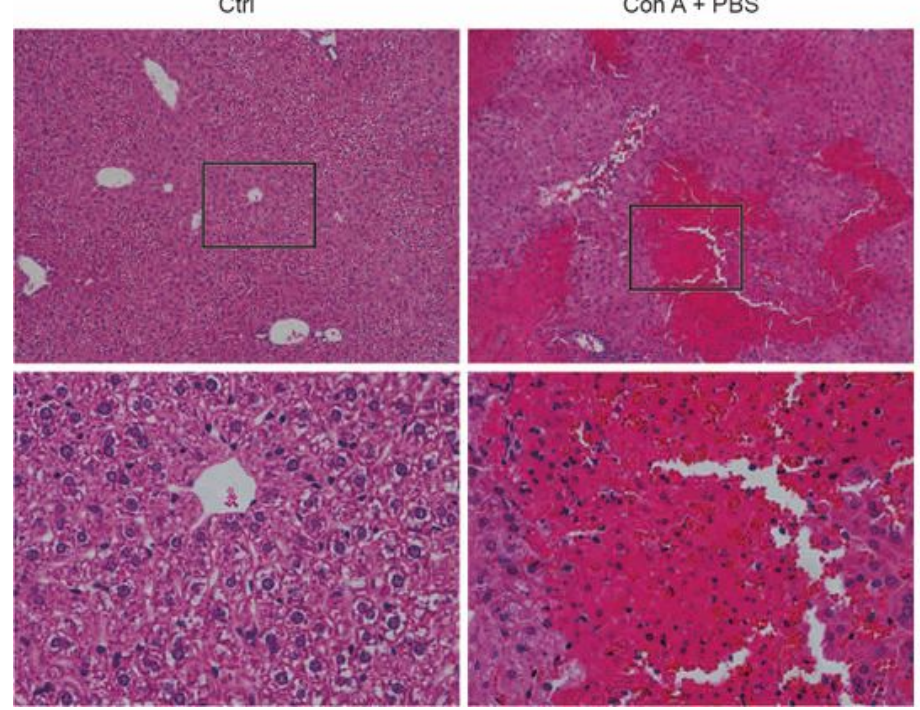

E

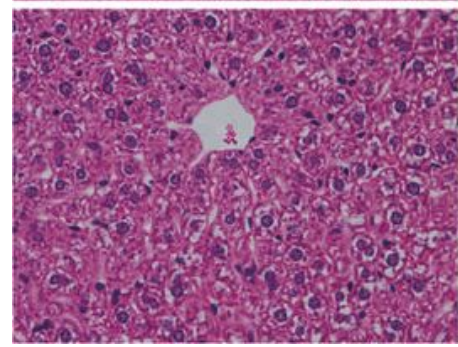

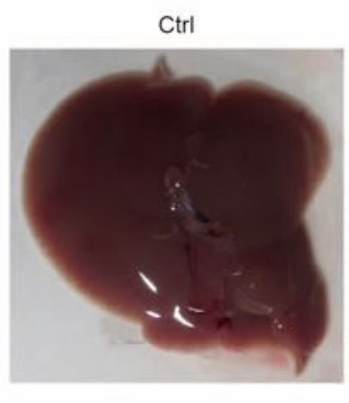
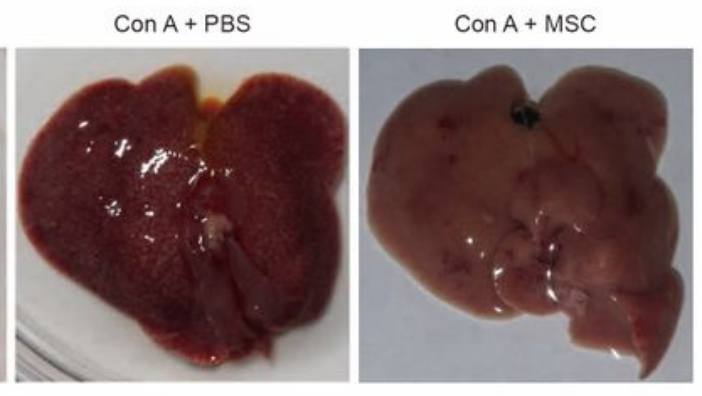

Con A + MSC
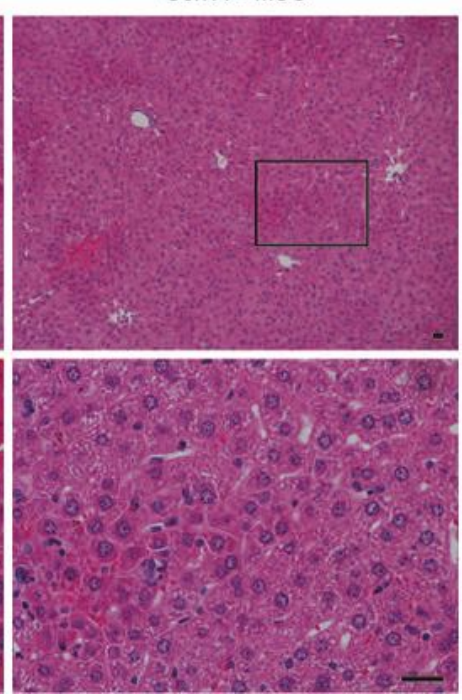

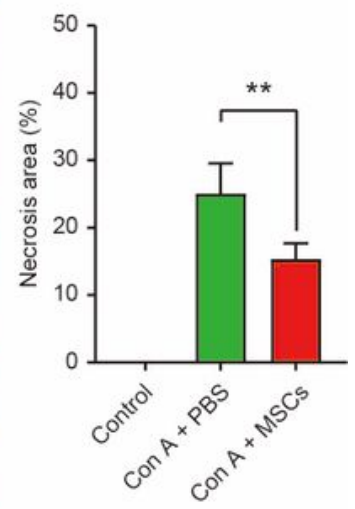

\section{Figure 1}

hUC-MSCs effectively protected mouse from Con A-induced fulminant hepatitis (A) Schematic illustration of experimental design. (B) The survival curves of mice in indicated groups within 120 hours after Con A administration. (C) \& (D) Serum AST (C) and ALT (D) levels were measured at indicated time points after Con A treatment in indicated groups. (E) Representative gross appearance of livers $24 \mathrm{~h}$ after Con A treatment in indicated groups. (F) Representative H\&E staining photographs (left) and quantification of 
necrosis area (right, $n=5 /$ group) of liver tissues $24 \mathrm{~h}$ after Con A administration in the indicated groups. Scale bar $=100 \mu \mathrm{M}$. Magnified images of the boxed areas were shown at the bottom. Data in (B - D) are shown as mean $\pm \operatorname{SD}(n=9-12 /$ group $)$ with the indicated significance $\left({ }^{\star} p<0.05,{ }^{*} p<0.01,{ }^{* *} p<0.001\right)$.

A

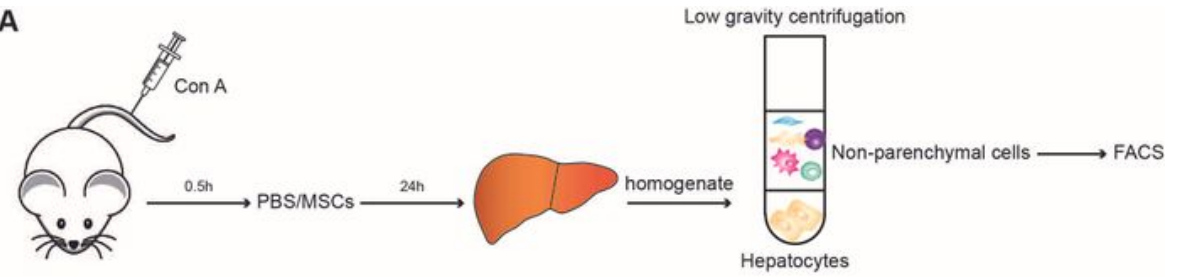

B
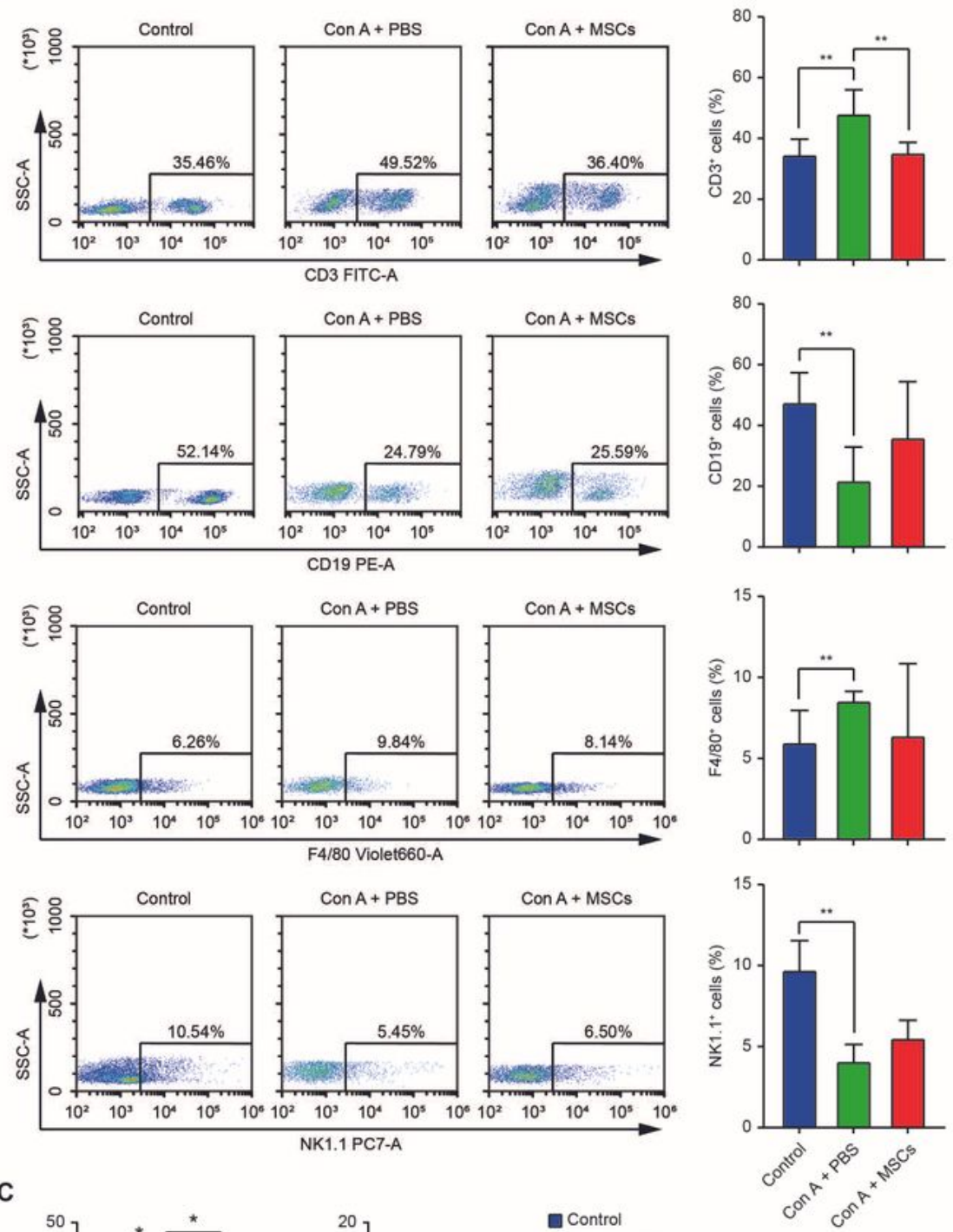

C

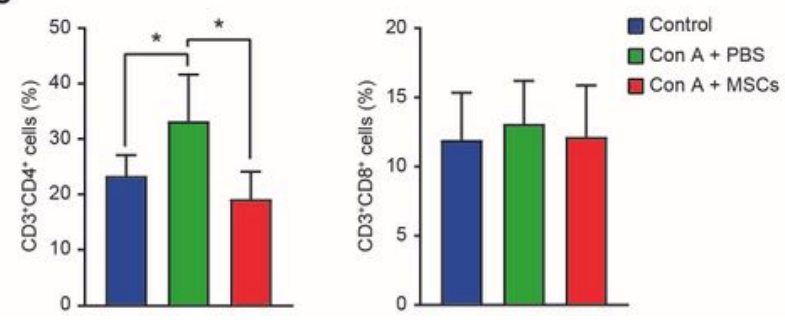

Figure 2

hUC-MSCs suppressed the activation of CD3+ hepatic T cells in Con A-induced fulminant hepatitis (A) Schematic illustration of experimental design. (B) Representative plots (left) and quantification (right) of 
flow cytometry analysis for CD3, CD19, F4/80 and NK1.1 expression in CD45+ liver non-parenchymal cells $24 \mathrm{~h}$ after Con A administration in indicated groups. (C) Quantification of flow cytometry analysis for $C D 3+C D 4+$ and $C D 3+C D 8+T$ cells ratio in $C D 45+$ liver non-parenchymal cells after Con $A$ administration in indicated groups. Data in (B) and (C) is shown as mean $\pm S D(n=5-9 /$ group) with the indicated significance $\left({ }^{\star} p<0.05,{ }^{* \star} p<0.01\right)$.

A

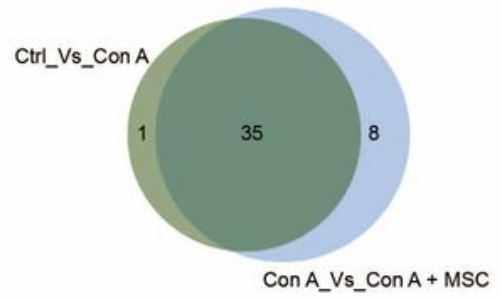

C
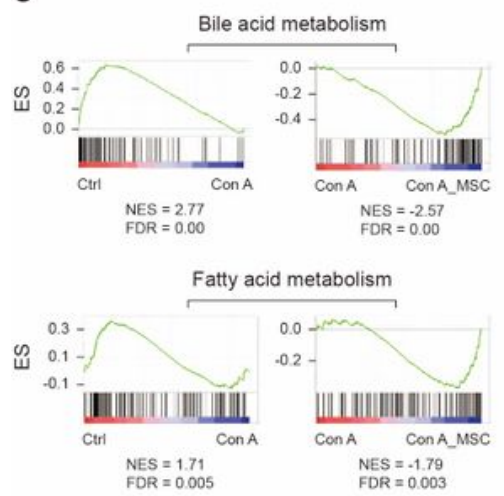

E
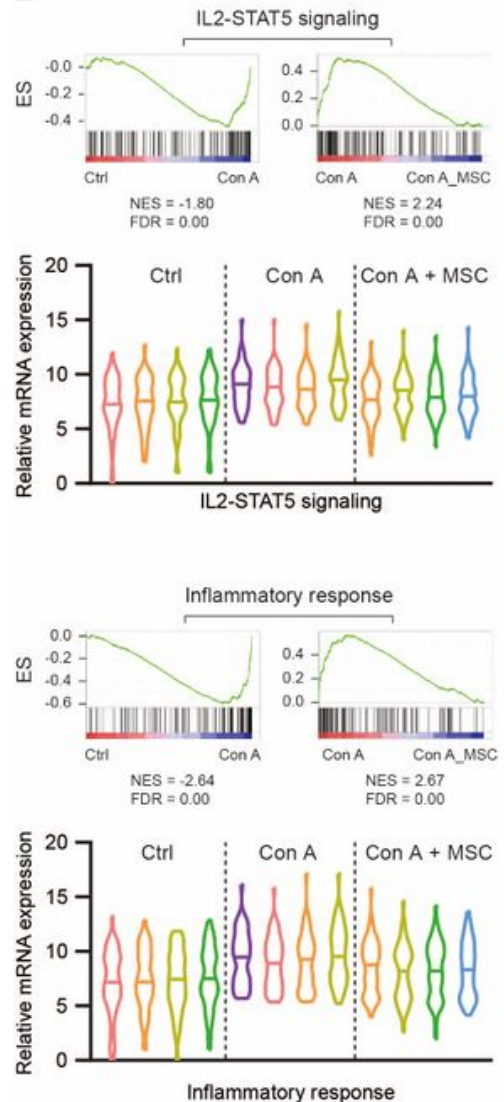

Inflammatory response
B
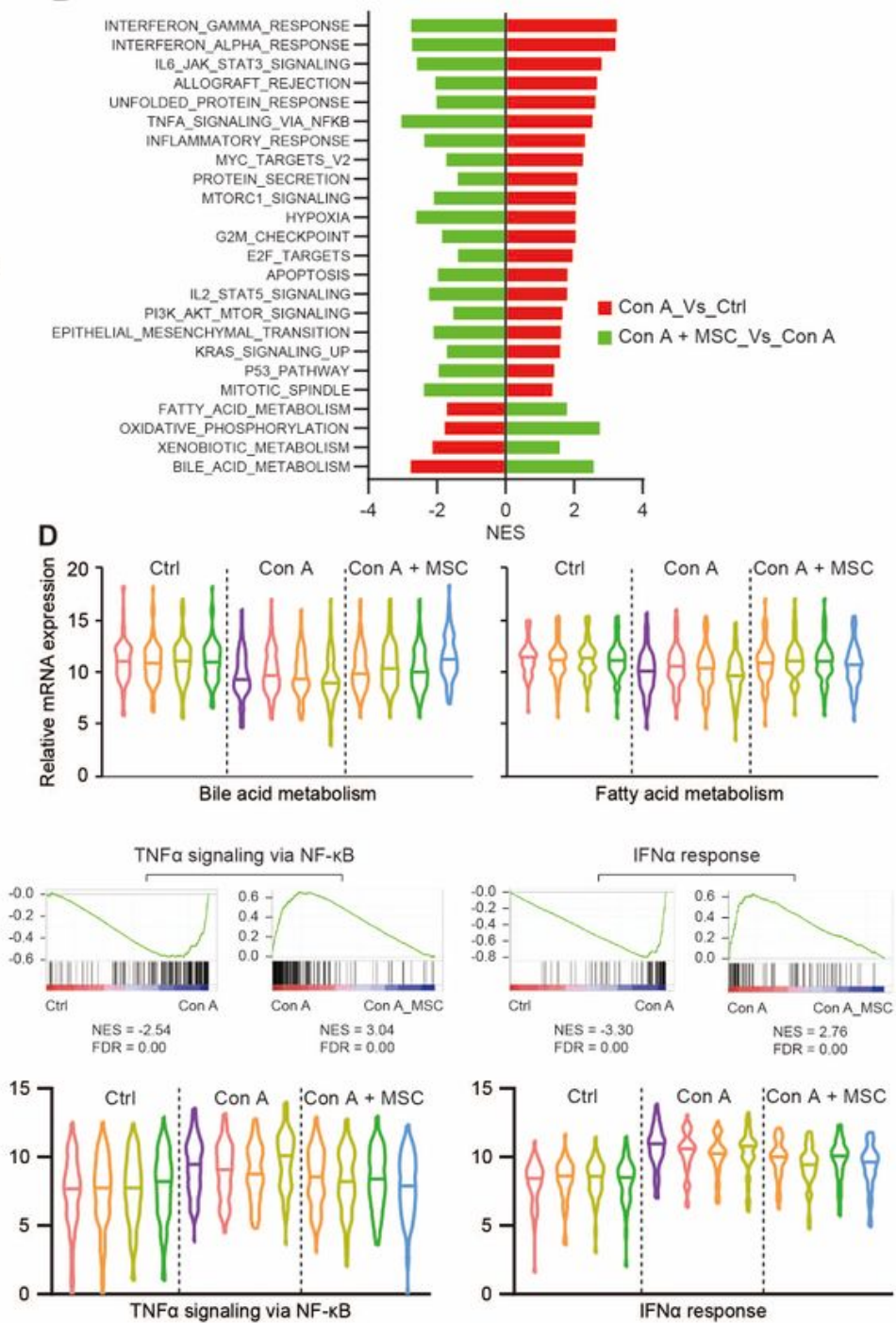

F
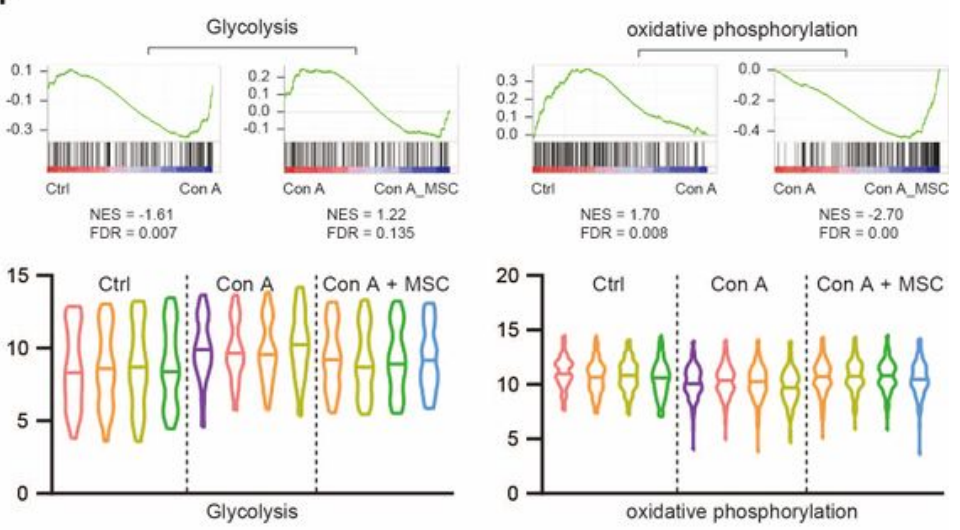

Figure 3 
RNA-sequencing of liver tissues showing alleviation of Con A-induced mouse liver injury by hUC-MSCs (A) Venn diagrams showing significantly enriched gene pathways of Control (Ctrl, also here after in similar experiments) versus Con A group and Con A versus Con A + MSC group by GSEA analysis. (B) Bar plot showing normalized enrichment score (NES) of significantly changed GSEA pathways of Control versus Con A group and Con A versus Con A + MSC group in GSEA analysis. (C \& D) GSEA analysis showing bile acid metabolism (upper) and fatty acid metabolism (lower) were enriched in indicated groups. (D) Violin plots showing relative mRNA level of genes involved in bile acid metabolism (left) and fatty acid metabolism (right) in indicated groups, 4 individuals were shown for each group. (E \& F) GSEA analysis showing enrichment of indicated gene sets (upper) and violin plots showing relative mRNA level of involved genes in indicated groups (lower). NES, normalized enrichment score; FDR, false discovery rate; GSEA, gene set enrichment analysis. 
A

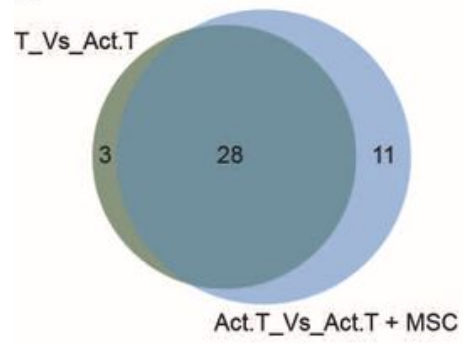

C

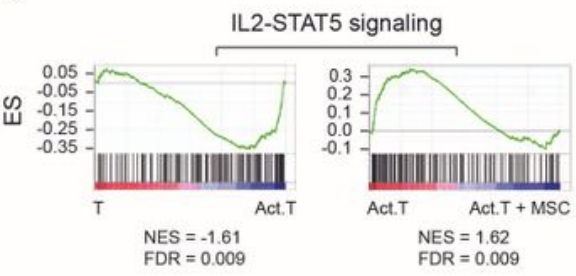

嵒

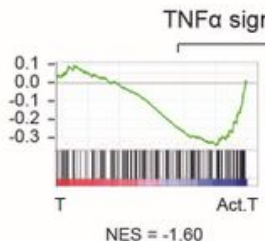

$\mathrm{FDR}=0.009$

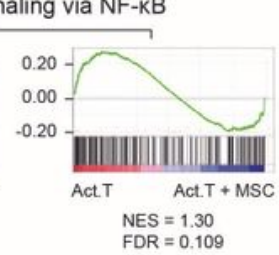

D

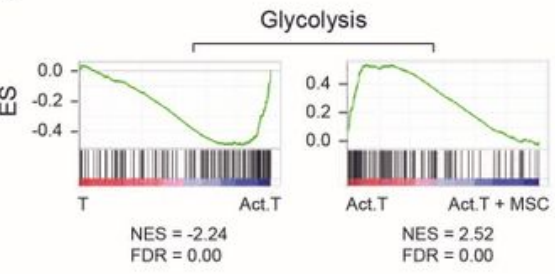

E

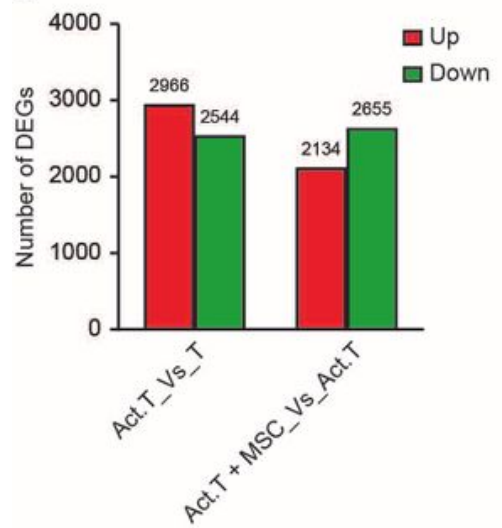

B

F
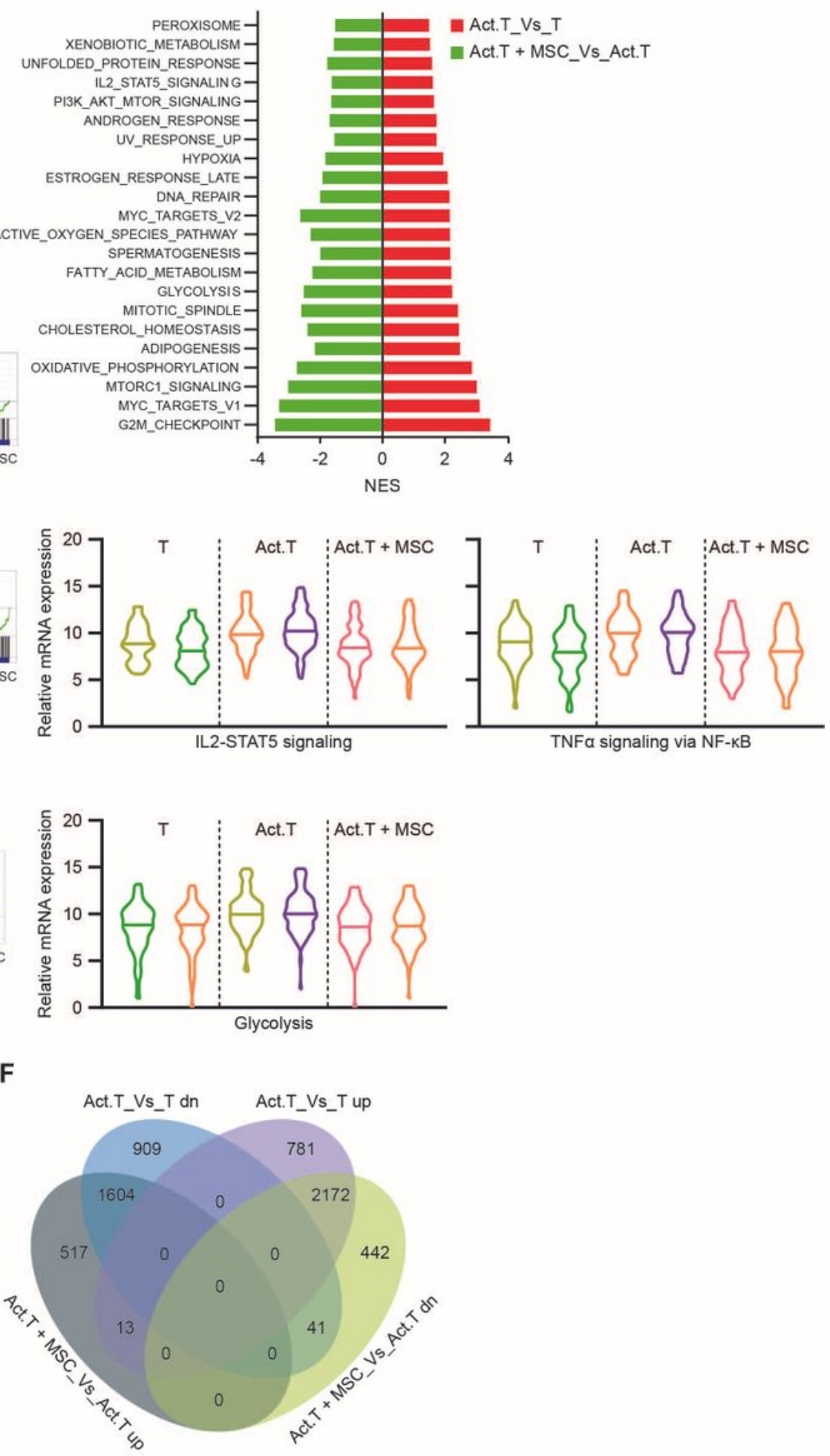

\section{Figure 4}

RNA-sequencing of human CD3+ T cells showing inhibition of T cell immunity by hUC-MSCs in vitro (A) Venn diagrams showing significantly enriched gene pathways of naïve T cells $(T)$ versus activated $T$ cells (Act.T) group and Act.T versus Act.T + MSC group by GSEA analysis. (B) Bar plot showing normalized enrichment score (NES) of significantly changed GSEA pathways of T versus Act.T group and Act.T versus Act.T + MSC group in GSEA analysis. (C) GSEA analysis showing IL2-STAT5 and TNFa signaling 
via NF-KB pathways were enriched in indicated groups (left). Violin plots showing relative mRNA level of genes involved in IL2-STAT5 and TNFa signaling via NF-KB in indicated groups, 2 replicates were shown for each group (right). (D) GSEA analysis showing glycolysis enrichment in indicated groups (left) and violin plots showing relative mRNA level of genes involved in glycolysis in indicated groups (right). (E) Summary of number of differentially expressed genes (DEGs) of Act.T versus T group and Act.T + MSC versus Act.T group. (F) Venn diagrams of the DEGs among different groups.

A

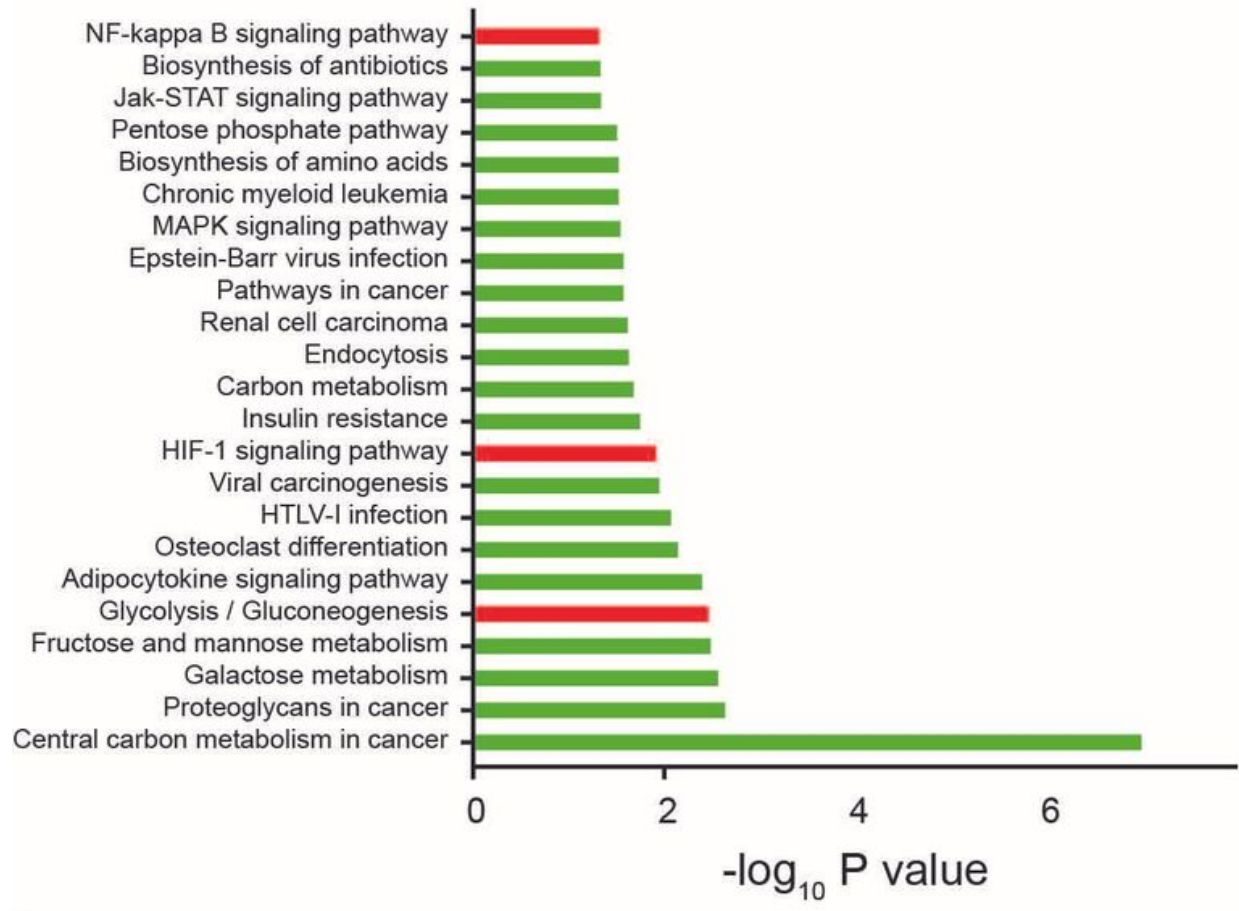

D

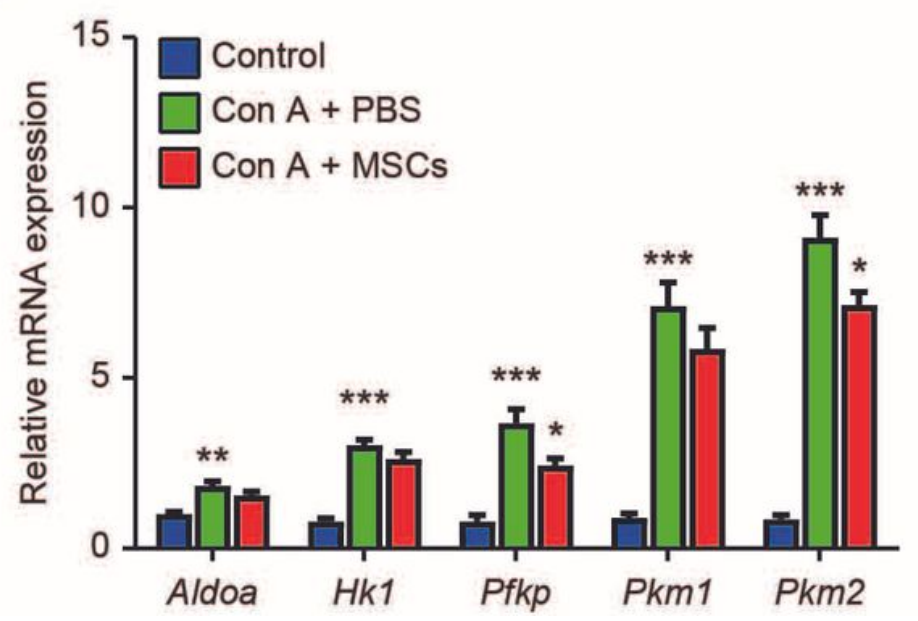

B

NF-KB signaling

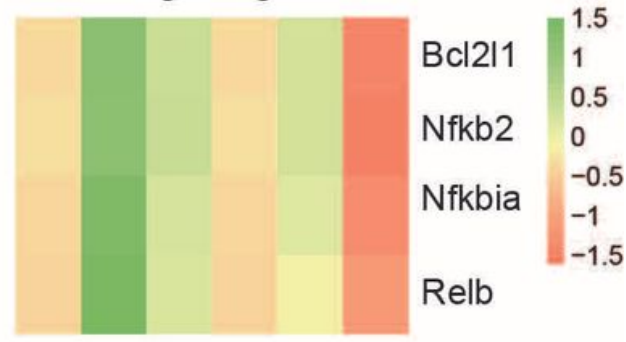

C

Glycolysis

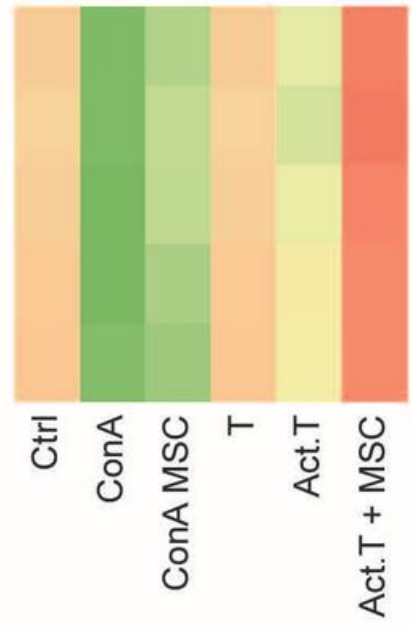

Aldoa

Hk1

Pfkl

Pfkp

$\mathrm{Pkm}$

\section{Figure 5}

NF-KB signaling and glycolysis are shared pathways between in vivo and in vitro models (A) KEGG pathway analysis of the overlapped DEGs between Con A + hUC-MSCs versus Con A + PBS group, Con A + PBS versus control group, activated T cells co-cultured with hUC-MSCs versus activated T cells and activated T cells versus naïve T cells. (B \& C) Heatmap showing expression of key genes of NF-KB signalling pathway (B) and glycolysis (C) in indicated groups. KEGG, Kyoto Encyclopaedia of Genes and 
Genomes. (D) RT-qPCR for key genes involved in glycolysis in mouse liver tissues in indicated groups ( $\mathrm{n}=$ 5 /group). Data in (C) is shown as mean $\pm S D$ with the indicated significance $\left({ }^{\star} p<0.05,{ }^{\star \star} p<0.01, \star \star \star p<<\right.$ $0.001)$.

\section{Supplementary Files}

This is a list of supplementary files associated with this preprint. Click to download.

- SupplementaryTable1.xls

- SupplementaryTable2.xls

- Supplementarymaterials.docx 